www.jmscr.igmpublication.org

Impact Factor (SJIF): 6.379

Index Copernicus Value: 79.54

ISSN (e)-2347-176x ISSN (p) 2455-0450

crossrefDOI: https://dx.doi.org/10.18535/jmscr/v6i10.102

Journal Of Medical Science And Clinical Research

IGM Publication

An Official Publication of IGM Publication

\title{
Clinical Profile and Visual Morbidity in Firecracker Eye Injuries
}

\author{
Authors \\ Dr Anjana Kumari ${ }^{1}$, Dr Kalpna Jain ${ }^{2 *}$, Dr Jaishree Murli Manoher ${ }^{3}$ \\ ${ }^{1}$ III $^{\text {rd }}$ Year Resident, ${ }^{2}$ Professor, ${ }^{3}$ Professor \& Head \\ Department of Ophthalmology, S.P. Medical College, Bikaner -334003 (Rajasthan) India \\ *Corresponding Author \\ Dr Kalpna Jain \\ Professor, S.P. Medical College, Bikaner-334003 (Rajasthan) India \\ Mobile No.: +91 9610598110, Email: anjanadhka@gmail.com
}

\begin{abstract}
Purpose: To study the clinical profile and visual morbidity in firecracker eye injuries.

Material and Methods: Hospital based prospective study of 32 patients came due to fire cracker injuries during 3 days of Deepawali festival in year 2017.

Results: Among 32 patients, Affected males were 27 and 5 patients were females. Twenty six patients were below thirty years.Bombs and fountains were the most common types of fireworks causing injury, affecting 26 patients (81.25\%), followed by rockets (9.37\%) and sparkles (9.37\%).The clinical presentations included lid swelling and conjunctival congestion (26 patients,81.25\%), corneal abrasions (15 patients, 46.87\%), corneal foreign bodies (11 patients,34.37\%), hyphema (11 patients, 34.37\%), laceration of lid and conjunctiva (4 patients, 12.5\%), vitreous haemorrhage (2 patients, 6.25\%). Open globe injury was observed in 2 patients (6.25\%). Iridodialysis was seen in 3 patients (9.37\%). After recovery Sixteen patients had visual acuity 6/6, 6 patients had 6/9-6/18, 2 patients had 6/24 and 6/60, 1 patient had 3/60, 3 patients had $<3 / 60$ perception of light and vision of 3 patient was not recorded, as they were not co-operative.

Conclusion: The firecraker injuries were common in younger age group and may cause significant visual morbidity. Firecracker injuries can be brought to a minimum by ignitiating them with proper safety measures, at safe distance and under parenteral supervision in children.
\end{abstract}

Keywords: Deepawali, firecracker injuries, visual morbidity.

\section{Introduction}

Firecrackers are extensively used in India during various festivals, ceremonies and social events, as is true the world over. They find a special place during Deepawali, which is an annual festival marking an important Hindu mythological event. Each and every individual is free to light the crackers wherever they desires. It is a well-known fact that whenever firecrackers are used, there is always a risk of burn and injury. The most common cause of eye injuries from firecrackers are caused by bombs and cone fountains.

Both bystanders and those involved in lighting the firecrackers are injured and most injuries were caused as a result of negligence by those igniting the firecrackers.

Accidents also happened when the devices malfunction and people tried to re-ignite them. 
Other reasons for accidents include a lack of safety measures, absence of parental supervision, and failure to maintain a safe distance from firecrackers when they were ignited. Firecrackers would also be lighted in the streets, as opposed to in safe and open public areas, putting bystanders at risk.

\section{Material and Methods}

This is a prospective, hospital based single centre study. The permission from institutional review board had taken and informed consent of patients were also taken. The study was conducted on 32 patients came due to fire cracker injuries during 3 days of Deepawali festival in year 2017.

The patients underwent a detailed ocular examination. Ultrasonography (USG) B scans, Gonioscopy and fundus photography and X-ray orbit was done as and when indicated.

Most of the patients with closed eye injuries were treated on an outpatient basis, patients with open eye injury were advised admission for further management and observation. Admitted cases included patients with corneal and scleral tears, traumatic iridodialysis with hyphema and suspected intraocular foreign body (IOFB).

Follow up of patients done till recovery. Follow up done at first week, second week, third week, one month, two month and maximum upto 3 month, according to the severity of injuries.

\section{Results}

Among 32 patients, Affected males were 27 and 5 patients were females. Twenty six patients were below thirty years .Bombs and fountains were the most common types of fireworks causing injury, affecting 26 patients $(81.25 \%)$, followed by rockets, 3 patients $(9.37 \%)$ and sparkles, 3 patients (9.37\%) [Table-1, Graph-1]. Twenty patients were actively involved in igniting the firecrackers, 10 were onlookers and 2 were accidentally involved. [Table-2,Graph-2]

Corneal abrasions and multiple foreign bodies involving lids and cornea were the most common presentations. The clinical presentations included lid swelling and conjuctival congestion (26 patients, $81.25 \%$ ), corneal abrasions (15 patients, 46.87\%), corneal foreign bodies (11 patients, $34.37 \%)$, hyphema (11 patients, $34.37 \%)$, laceration of lid and conjunctiva (4 patients, $12.5 \%$ ), vitreous haemorrhage (2 patients, $6.25 \%$ ). Open globe injury was observed in 2 patients (6.25\%). Iridodialysis was seen in 3 patients (9.37\%). [Table-3]. However, sparkles produced only conjunctival or corneal burn or corneal abrasions without affecting the visual recovery, while rockets, fountains and bombs caused lid laceration, open globe injury, iridodialysis, angle recession, vitreous haemorrhage and multiple corneal foreign bodies, all of which led to poor visual outcome.

\section{Visual outcome}

According to the initial assessment of vision, at the time of presentation to the hospital 10 patients had visual acuity $6 / 6,6$ patient had $6 / 9$ to $6 / 18,4$ patients had $6 / 24$ to $6 / 60,3$ patients had $5 / 60$ to $3 / 60,6$ patients had $<3 / 60$ to perception of light. Vision of three patients was not recorded, as they were not co-operative at the time of initial assessment. Final vision was noted after maximum possible recovery. After recovery Sixteen patients had visual acuity $6 / 6,6$ patients had 6/9-6/18, 2 patients had 6/24 and 6/60, 1 patient had 3/60, 3 patients had <3/60-perception of light and vision of 3 patient was not recorded. [Table-4]

Table 1: Type of Firecracker injury according to Age

\begin{tabular}{|l|c|c|c|c|c|}
\hline Type of fire crackers & Upto 10 years & 11-20 years & 21-30 years & $>30$ & Total \\
\hline Bomb & 4 & 7 & 5 & 5 & 21 \\
\hline Fountain & 2 & 2 & 1 & 0 & 5 \\
\hline Rocket & 0 & 1 & 1 & 1 & 3 \\
\hline Sparkles & 2 & 1 & 0 & 0 & 3 \\
\hline Total & 8 & 11 & 7 & 6 & 32 \\
\hline
\end{tabular}


[Figure 1]

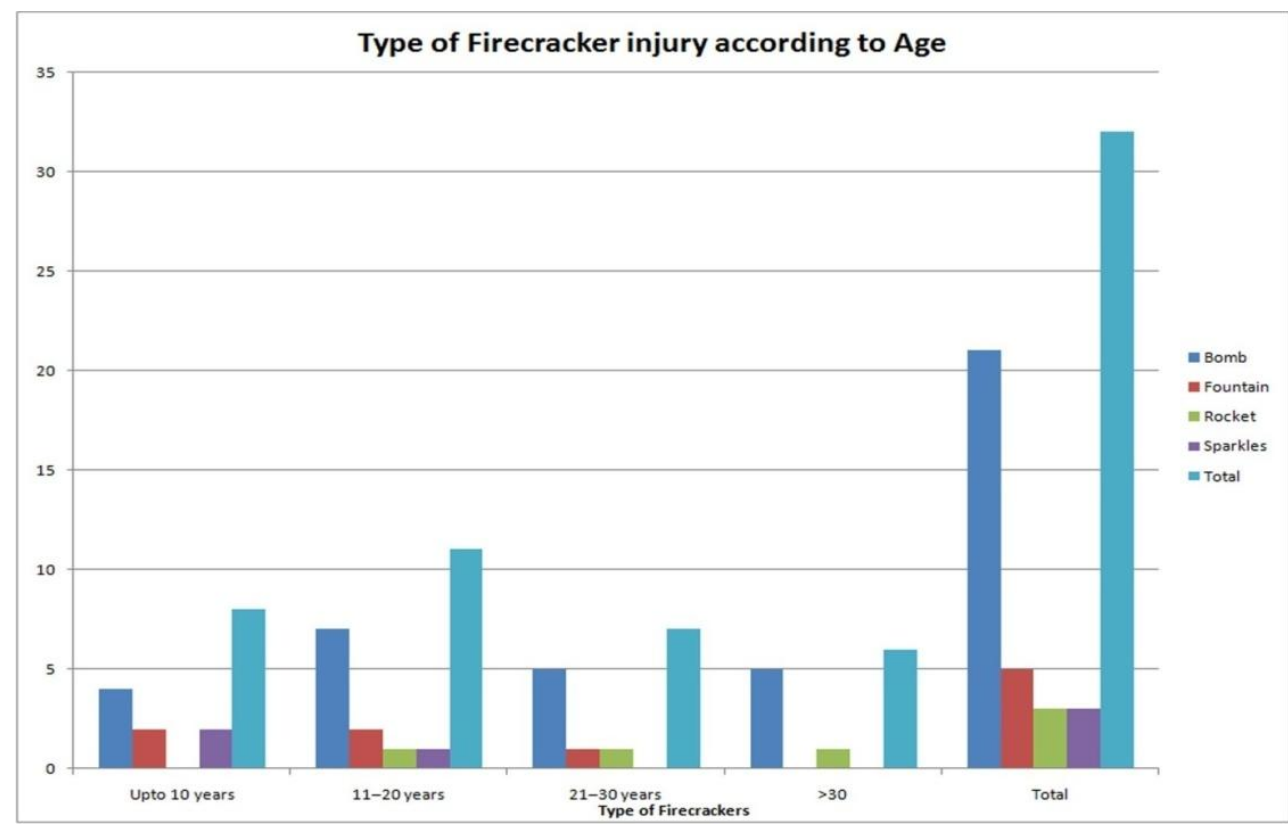

Table 2: Mode of Injury

\begin{tabular}{|l|c|}
\hline Type of Fire crackers & No. of Cases \\
\hline Self discharging crackers & 20 \\
\hline Onlookers & 10 \\
\hline Accidental & 2 \\
\hline
\end{tabular}

\section{[Figure 2]}

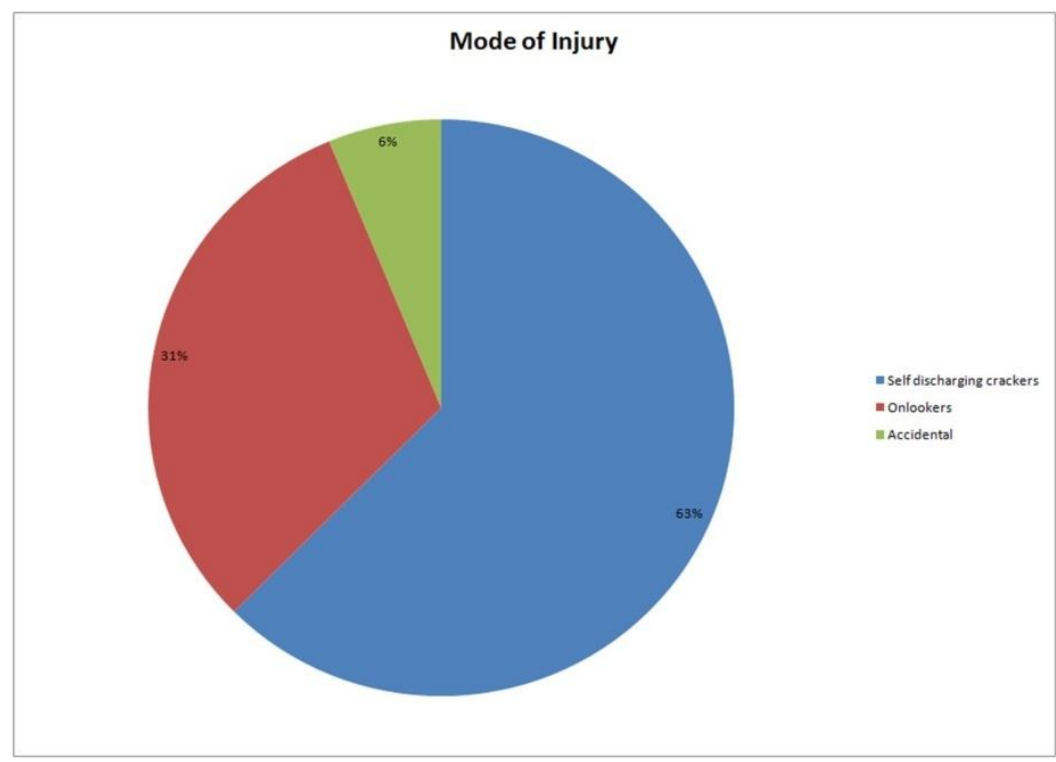

Table 3: Various Manifestation of Fire cracker injury

\begin{tabular}{|l|c|c|}
\hline Type of Injury & No. of Cases & Percentage \\
\hline Lid swelling and conjunctival congestion & 26 & $81.25 \%$ \\
\hline Laceration of lid and conjunctiva & 4 & $12.5 \%$ \\
\hline Corneal abrasion & 15 & $46.87 \%$ \\
\hline Multiple corneal foreign body & 11 & $34.37 \%$ \\
\hline Hyphema & 11 & $34.37 \%$ \\
\hline Iridodialyasis & 3 & $9.37 \%$ \\
\hline Vitreous haemorrhage & 2 & $6.25 \%$ \\
\hline Open globe injury & 2 & $6.25 \%$ \\
\hline
\end{tabular}


In all, 5 patients were admitted to our hospital with firework injuries. Two of these patients underwent surgical repair for corneal and scleral tear. Visual outcome in all these cases was poor. In one patient with total hyaphema, anterior chamber wash was done. Two others were treated conservatively as per the standard treatment protocol for ocular burns and chemical injuries. Injured eyes were irrigated with copious amount of normal saline and particulate matter and soot particles were removed with forceps under local anesthesia; $\mathrm{pH}$ was monitored before and after ocular irrigation. Patients were prescribed antibiotic steroid eye drops (tapered after a week), lubricating solution and ointment, cycloplegic eye drops and oral anti-inflammatory drugs. Later, one patient underwent lid reconstruction for correction of cicatricial entropion.

Table-4: Visual outcome

\begin{tabular}{|l|c|c|}
\hline Visual acuity & $\begin{array}{c}\text { At the time of } \\
\text { presentation } \\
\text { (no. of patients) }\end{array}$ & $\begin{array}{c}\text { At the time of } \\
\text { recovery } \\
\text { (no. of patients) }\end{array}$ \\
\hline $6 / 6$ & 10 & 16 \\
\hline $6 / 9-6 / 18$ & 6 & 7 \\
\hline $6 / 24-6 / 60$ & 4 & 2 \\
\hline $5 / 60-3 / 60$ & 3 & 1 \\
\hline $\begin{array}{l}<3 / 60-\text { perception } \\
\text { of light }\end{array}$ & 6 & 3 \\
\hline Not recorded & 3 & 3 \\
\hline
\end{tabular}

\section{Discussion}

This study was a hospital-based, single-centre, prospective case series of firecracker injuries. ${ }^{[8-10]}$ Most of the patients were below the age of 20 years. $^{[7]}$ Firecrackers injury were more in males ${ }^{[1,2,4]}$ as observed in our study as well. Most of the victims in our study were actively involved in igniting the firecrackers. ${ }^{[3,5]}$ Most common firecracker injury in this study were bombs followed by fountains and other firecrackers. Unlike some studies, where sparkles were not found to be innocent, were reported to cause minimal injury in our study. ${ }^{[7]}$ The injuries were ranged from conjuctival or corneal burns to globe rupture. Interventations done ranging from eye wash to repair of open globe injuries.

In India mostly firework related injuries are reported during deepawali. ${ }^{[1,2]}$ Many of injuries were caused due to negligence of those igniting the firecrackers, lack of safety measures and not following them was a reason for eventualities. Absence of parenteral supervision, and failure to maintain safe distance from firecracker were contributory in some cases of injury. The other cause of injury is the common practice of igniting firecrackers in streets thus exposing the passerby. Those who watch fireworks displays should maintain a safe distance and use protective eye wears. ${ }^{[4]}$ Parents should supervise their wards. Public firework displays injuries are extremely rare. ${ }^{[6]}$ Regulating the quality of fireworks and promoting safe use via schools and media will also have a positive impact.

\section{Conclusion}

The firecraker injuries were common in younger age group and may cause significant visual morbidity. Firecracker injuries can be brought to a minimum by igniting them with proper safety measures, at safe distance and under parenteral supervision in children.

\section{Acknowledgement}

I am thankful to Dr. J.M. Manoher and Dr. Kalpna Jain for their kind support.

\section{Conflict of Interest: None}

\section{References}

1. Mohan K, Dhir SP, Munjal VP, Jain IS. Ocular fireworks injuries in children. AfroAsian J Ophthalmol 1984;2:162-65.

2. Dhir SP, Shishko MN, Krewi A, Mabruka S. Ocular fireworks in children. J Paediat Ophthalmol Strabismus 1991;28:1-2.

3. Witsaman RJ, Comstock RD, Smith GA. Pediatric fireworks related injuries in the United States: 1990-2003. Pediatrics. 2006;118:296-303.

4. Wilson RS. Ocular fireworks Injuries. Am J Ophthalmol 1975;79:449-51.

5. Mansouri MR, Mohammadi SF, Hatef E, Rahbari H, Khazanehdari MS, Zandi P, et 
al. The Persian Wednesday Eve Festival "Charshanbe-Soori" Fireworks Eye Injuries: A Case Series. Ophthalmic Epidemiol. 2007;14:17-24.

6. Sundenlin K, Norrsell K. Eye injuries from fireworks in Western Sweden. Acta Ophthalmologica Scandinavica 2000;78:61-64.

7. Ravi Kumar, Manohar Puttanna, K S Sriprakash, B L Sujatha Rathod, and Venkatesh C Prabhakaran. Indian J Ophthalmol. 2010 Mar-Apr; 58(2):157159.

8. Puri V, Mahendru S, Rana R, Deshpande M. Firework injuries: A ten-year study. J Plastic Reconstr Aesthet Surg. 2008; 62:1103-11.

9. Sacu S, Segur-Eitz N, Stenng K, Zehetmayer M. Ocular firework injuries at New year's eve. Ophthalmologica 2002;216:55-9.

10. Witsaman RJ, Comstock RD, Smith GA. Pediatric fireworks related injuries in the United States: 1990 2003. Pediatrics 2006;118:296-303. 